\title{
Desempenho de cultivares de arroz com uso de reguladores de crescimento, em diferentes sistemas de cultivo
}

\author{
Mara Grohs ${ }^{(1)}$, Enio Marchesan ${ }^{(1)}$, Rodrigo Roso(1), Tiago Constante Formentini(1) \\ e Maurício Limberger de Oliveira ${ }^{(1)}$
}

\begin{abstract}
(1)Universidade Federal de Santa Maria, Avenida Roraima, no 1.000, CEP 97105-220 Santa Maria, Rio Grande do Sul, RS. E-mail: maragrohs@yahoo.com.br, emarchezan@terra.com.br, rodrigo.roso@hotmail.com, tiagoformentini@hotmail.com, mauriciodeoliveira8@hotmail.com
\end{abstract}

\begin{abstract}
Resumo - O objetivo deste trabalho foi avaliar o efeito de reguladores de crescimento sobre o estabelecimento inicial e o desempenho agronômico de cultivares de arroz irrigado, em diferentes sistemas de cultivo. O experimento foi conduzido em ambiente controlado e em campo, com as cultivares Irga 424 e Irga 425, e os produtos ácido giberélico, tiametoxam e Haf Plus. Em campo, os tratamentos foram testados nos sistemas de cultivo convencional e pré-germinado. Em ambiente controlado, as substâncias avaliadas promoveram a germinação de Irga 425, com incremento de 50\% na germinação com o uso de tiametoxam, e de 39\% com Haf Plus e ácido giberélico. Em campo, esse desempenho foi dependente do sistema de cultivo e da cultivar utilizada. O ácido giberélico causou estiolamento inicial, com reflexos na estatura da planta, na emissão de perfilhos e na deposição de biomassa vegetal. Tiametoxam e Haf Plus estimularam o perfilhamento das cultivares de arroz, nos dois sistemas de cultivo. Apesar de todos os produtos estimularem o número de panículas por metro quadrado, sua influência na produtividade de grãos não foi observada nos sistemas avaliados.
\end{abstract}

Termos para indexação: Oryza sativa, ácido giberélico, estabelecimento inicial, sistema pré-germinado, tiametoxam.

\section{Performance of rice cultivars with the use of growth-regulators in different cropping systems}

\begin{abstract}
The objective of this work was to evaluate the effect of growth-regulating substances on initial establishment and agronomic performance of irrigated rice cultivars, in different cropping systems. The experiment was carried out in controlled environment and in field conditions, using the cultivars Irga 424 and Irga 425, and the products gibberellic acid, thiamethoxam and Haf Plus. At field, treatments were tested with conventional and pre-germinated sowing systems. In the controlled environment, the evaluated substances promoted the germination of Irga 425, with an increase of 50\% in germination with the use of thiamethoxam and of $39 \%$ with Haf Plus and gibberellic acid. In the field, this performance was dependent on the system and the cultivar used. Gibberellic acid caused initial blanching, which reflected in plant height, tiller emission, and deposition of vegetal biomass. Thiamethoxam and Haf Plus stimulated tillering of rice cultivars in both cultivation systems. Although all the products stimulated the number of panicles per square meter, there is no influence on grain yield in the evaluated systems.
\end{abstract}

Index terms: Oryza sativa, gibberellic acid, early establishment, pre-germinated system, thiamethoxam.

\section{Introdução}

Além do estresse causado por baixas temperaturas, o estabelecimento das plântulas de arroz (Oryza sativa L.) pode ser afetado por diversos outros fatores. Características intrínsecas de cada genótipo de arroz podem condicionar plântulas mais ou menos vigorosas, o que está associado a balanços hormonais. Porém, a atuação do ambiente sobre a semente também é de grande importância.
No sistema pré-germinado, é comum o acamamento das plantas, o que pode ser agravado por fatores como: ação do vento e da chuva, excesso de nitrogênio, altura da lâmina de água e características genéticas de cada cultivar (Ismail et al., 2009). $\mathrm{O}$ vento e a chuva, quando causam acamamento, contribuem para a diminuição da produtividade da cultura (Marchezan et al., 2004). Entre os fatores genéticos afetados, destacam-se a estatura da planta, o peso da panícula e, principalmente, a formação

Pesq. agropec. bras., Brasília, v.47, n.6, p.776-783, jun. 2012 
de sistema radicular adequado, amplo e profundo (Tinarelli, 1989).

A manutenção da lâmina de água dificulta o desenvolvimento e a fixação das plântulas de arroz, que se desprendem do solo e passam a flutuar na superfície (Farooq et al., 2011). Nesse sentido, há relatos de que a retirada da água após a semeadura seria eficiente no estabelecimento da lavoura no sistema pré-germinado (Silva et al., 2002), ao promover melhor fixação de plantas. No entanto, a retirada da água pode prejudicar o estabelecimento da lavoura de arroz irrigado no sistema pré-germinado, além de aumentar a possibilidade de perdas por infestação de invasoras (Marchezan et al., 2007). Portanto, é necessário aumentar o vigor inicial e o enraizamento das plântulas, para evitar o estiolamento e o comprometimento do estabelecimento inicial.

Os hormônios ou biorreguladores atuam em todas as fases de desenvolvimento das plantas, e o conhecimento de seus efeitos fisiológicos é fundamental para a compreensão da vida dos vegetais. Novas descobertas têm estimulado a utilização dessas substâncias na produção agrícola, com vistas ao aumento da qualidade e sustentabilidade dos cultivos. Promotores e inibidores do crescimento, reguladores de maturação e bioestimulantes vegetais têm composto diversos sistemas de produção, como os de algodão, cana-de-açúcar, soja, citros, manga, uva, flores, hortaliças, entre outros. Dependendo de seu modo de ação, essas substâncias podem estimular a germinação das sementes por meio da quebra de dormência (Külen et al., 2011) ou de estímulos ao metabolismo de enzimas hidrolíticas, que controlam etapas da divisão celular, como as giberelinas (O'Brien et al., 2010), ou que induzem processos de autodefesa da planta, como os inseticidas da classe dos neonicotinoides (Ford et al., 2010). Assim, a utilização dessas substâncias em sistemas de cultivo em que o estabelecimento inicial do arroz irrigado é dificultado, pode ser uma estratégia interessante para garantir o estande de plantas.

O objetivo deste trabalho foi avaliar o efeito de reguladores de crescimento sobre o estabelecimento inicial e o desempenho agronômico de cultivares de arroz irrigado, em diferentes sistemas de cultivo.

\section{Material e Métodos}

A primeira parte do experimento foi conduzida em laboratório, no Departamento de Fitotecnia da Universidade Federal de Santa Maria, com uso de câmera de incubação tipo "biochemical oxygen demand" (BOD), em agosto de 2010.

Nesse ambiente, o experimento foi conduzido em arranjo bifatorial $(2 \times 4)$, com quatro repetições, em delineamento inteiramente casualizado. As cultivares de arroz irrigado avaliadas foram Irga 424 e Irga 425, indicadas para os sistemas convencional e pré-germinado, respectivamente. Foram utilizadas sementes certificadas do Instituto Rio Grandense do Arroz, com pureza de $98 \%$ e germinação em condições normais de $90 \%$. Os tratamentos consistiram da aplicação nas sementes de três substâncias com efeito regulador do crescimento: ácido giberélico, tiametoxam (Cruiser) e Haf Plus. Além disso, foi avaliado um tratamento controle, sem aplicação de nenhuma substância.

$\mathrm{O}$ ácido giberélico, na sua forma $\mathrm{AG}_{3}$, foi escolhido por ser considerado o hormônio da germinação; o tiametoxam, inseticida da classe dos neonicotinoides, foi incluído no trabalho por seu efeito enraizador, principalmente em condição de estresse ambiental; e o Haf Plus, um fertilizante organo-mineral, foi selecionado por ser constituído de extratos naturais e algas, os quais podem conferir efeitos variados dentro da planta, desde hormonal até nutricional. O Haf plus é uma mistura formulada de nitrogênio $(5 \%)+$ matéria orgânica (25\%), L- $\alpha$ aminoácidos livres $(6 \%)$, extrato de algas Ascophyllum nodosum (Linnaeus) Le Jolis, polissacarídeos e micronutrientes $(0,72 \%)$.

A dose utilizada de tiametoxam e Haf Plus foi de $200 \mathrm{~mL} 100 \mathrm{~kg}^{-1}$ de sementes, e a de ácido giberélico

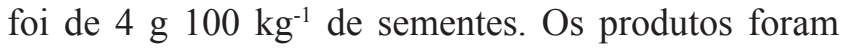
aplicados diretamente nas sementes com válvula pressurizada, 24 horas antes da semeadura, com o volume de calda de 4,6 L $100 \mathrm{~kg}^{-1}$ de sementes. Após os tratamentos, foram avaliados os efeitos dos produtos, por meio do emprego de testes de germinação e da determinação do comprimento da parte aérea e da raiz das plântulas. As sementes foram germinadas a $17^{\circ} \mathrm{C}$, temperatura mínima do solo exigida para a realização da semeadura do arroz (Arroz irrigado, 2010).

A germinação foi registrada aos 7, 10 e 14 dias após a semeadura (DAS), tendo sido consideradas germinadas as sementes cuja radícula e cujo coleóptilo alcançaram $2 \mathrm{~cm}$ de comprimento, segundo especificações das Regras para análises de sementes (2009). Os resultados foram expressos em percentagem de plântulas germinadas. 
Para avaliar o comprimento da raiz e da parte aérea das plântulas, foram utilizadas quatro repetições de dez sementes. Os rolos com as sementes permaneceram por 14 dias em BOD, tendo sido avaliados, a cada 72 horas, o comprimento radicular e da parte aérea das plântulas normais. A mensuração foi iniciada quando se constatou $50 \%$ de sementes germinadas.

Os tratamentos testados em ambiente controlado foram levados a campo, em área de várzea, em solo classificado como Planossolo Háplico eutrófico arênico, pertencente à unidade de mapeamento Vacacaí (Santos et al., 2006). Nesse ambiente, foram conduzidos dois experimentos, alocados lado a lado, que diferiram apenas quanto ao sistema de cultivo utilizado: convencional ou pré-germinado. Utilizou-se o delineamento experimental de blocos ao acaso, com cinco repetições.

Para a implantação do sistema pré-germinado e convencional, em 1/8/2010, o solo foi submetido a gradagens e aplainamento com prancha alisadora. No mesmo dia, para o sistema pré-germinado, iniciou-se a irrigação por submersão da área experimental, tendose mantido essa condição até o final do experimento. No sistema convencional, a irrigação foi iniciada quando as plantas de arroz encontravam-se no estádio V4, segundo escala de Counce et al. (2000).

A semeadura das cultivares ocorreu em 1/10/2010, quando a temperatura do solo e da água atingiu $17^{\circ} \mathrm{C}$. A densidade de semeadura utilizada correspondeu a $90 \mathrm{~kg} \mathrm{ha}^{-1}$ de semente. As parcelas tinham dimensões de $1,87 \times 5 \mathrm{~m}\left(7,85 \mathrm{~m}^{2}\right)$, com área útil de $5 \mathrm{~m}^{2}$, para a estimativa da produtividade de grãos. No sistema convencional, utilizou-se o espaçamento entre plantas de $0,175 \mathrm{~m}$ entrelinhas. No sistema pré-germinado, a semeadura foi realizada a lanço, com as sementes previamente germinadas quando a radícula apresentava em torno de $2 \mathrm{~mm}$ de comprimento. Os demais tratos culturais foram realizados conforme recomendação para o cultivo de arroz irrigado (Arroz irrigado, 2010).

Aos dez dias após a emergência, foi demarcado $1 \mathrm{~m}$ de linha de semeadura em cada unidade experimental, no sistema convencional, e uma área de $0,25 \times 0,25 \mathrm{~m}$ no sistema pré-germinado, nas quais se realizou a contagem do estande inicial, a qual foi posteriormente convertida para $\mathrm{m}^{2}$. Além disso, nessa área, realizouse a contagem do número de colmos por planta em V4, V5 e V9, nos dois experimentos, e do número de panículas por ocasião da pré-colheita, aos 115 dias após a emergência. Na mesma ocasião, avaliou-se a estatura de dez plantas escolhidas ao acaso.

Para a avaliação de massa de matéria seca e estatura de plantas, foi demarcado outro metro de linha de semeadura, do qual foram retiradas dez plantas em sequência, a cada avaliação, no sistema convencional. No sistema pré-germinado, as plantas foram retiradas em sequência, do lado oposto ao escolhido para a avaliação de estande inicial e colmos. Após arrancadas, as plantas foram lavadas - tendo-se retirado as raízes - e medidas da base até a ponta da última folha, para se obter a estatura das plantas do estádio V1, V3 e V5, segundo escala de Counce et al. (2000). Após medidas, as plantas foram colocadas em sacos de papel e, em seguida, levadas à estufa de circulação forçada de ar com temperatura de $65^{\circ} \mathrm{C}$, para secagem até peso constante, para determinação da massa de matéria seca das plantas.

A produtividade de grãos foi determinada por meio da colheita manual das plantas, quando os grãos atingiram umidade média de $20 \%$. As plantas foram trilhadas e, posteriormente, determinou-se a massa dos grãos, com correção da umidade para $13 \%$. A análise estatística foi realizada por meio do teste de Scott-Knott, a 5\% de probabilidade. As variáveis percentagem de germinação e esterilidade de espiguetas foram transformadas pela equação $\mathrm{yt}=(y+1)^{0,5}$.

\section{Resultados e Discussão}

$\mathrm{Na}$ primeira contagem de plântulas normais, realizada aos 7 DAS, todas as substâncias com efeito de regulador de crescimento foram eficientes em estimular a germinação das cultivares de arroz, com destaque para o tiametoxam (Tabela 1). Porém, esse estímulo foi maior para a cultivar Irga 425, com diferença de 48\% em comparação à testemunha. No caso do tiametoxam e do ácido giberélico, esse estímulo à germinação era esperado, pois essas substâncias atuam em diferentes etapas do processo germinativo, principalmente com estímulo da atividade de enzimas-chave envolvidas nesse processo (Horii et al., 2007; Rayorath et al., 2008; Macedo \& Castro, 2011). Aos 10 DAS, a influência dos produtos passou a ser dependente da cultivar utilizada. Em 'Irga 424', independentemente do produto utilizado, a germinação não diferiu da testemunha até o final do experimento. Essa cultivar é classificada como sensível ao frio e de vigor inicial baixo (Cruz 
et al., 2010), o que pode ter prejudicado sua interação com os produtos utilizados. Para a cultivar Irga 425, o tiametoxam e o ácido giberélico aumentaram em $60 \%$ a germinação das sementes, enquanto o Haf Plus apresentou comportamento intermediário (46\%).

Ao final da avaliação da germinação, aos 14 DAS, a percentagem de sementes germinadas de Irga $425 \mathrm{com}$ o tiametoxam foi $50 \%$ maior que a da testemunha, com comportamento intermediário para ácido giberélico e Haf Plus (39\%). Esse resultado pode ser atribuído ao fato de que, para que a planta fosse considerada germinada, tanto a parte aérea quanto o sistema radicular deveriam apresentar ao menos $2 \mathrm{~cm}$ de comprimento. Como as giberelinas (ácido giberélico) são eficientes em estimular o alongamento do mesocótilo, por conferir rápido desenvolvimento da parte aérea das plântulas (Yamagushi, 2008; Dai \& Xu, 2010), esse efeito pode, em um primeiro momento, estimular o desenvolvimento radicular. Isso porque a presença de ácido giberélico atua sobre a atividade das citocininas, hormônio responsável pelo crescimento das raízes

Tabela 1. Percentagem de germinação e comprimento da parte aérea e da raiz das cultivares de arroz irrigado Irga 424 e Irga 425, submetidas a tratamento de sementes com substâncias com efeito de reguladores de crescimento, aos 7, 10 e 14 dias após a semeadura (DAS) ${ }^{(1)}$.

\begin{tabular}{|c|c|c|c|c|c|c|}
\hline \multirow[t]{2}{*}{ Tratamento } & \multicolumn{2}{|c|}{7 DAS } & \multicolumn{2}{|c|}{10 DAS } & \multicolumn{2}{|c|}{14 DAS } \\
\hline & Irga 424 & Irga 425 & Irga 424 & $\operatorname{Irga} 425$ & Irga 424 & Irga 425 \\
\hline & \multicolumn{6}{|c|}{ Germinação (\%) } \\
\hline Testemunha & $0 \mathrm{~d}^{\mathrm{ns}(2)}$ & $0 \mathrm{~d}^{\mathrm{ns}}$ & $60 \mathrm{~A}^{\mathrm{ns}}$ & $9 \mathrm{Bc}$ & $65 \mathrm{~A}^{\mathrm{ns}}$ & $24 \mathrm{Bd}$ \\
\hline Tiametoxam & $34 \mathrm{Ac}$ & $20 \mathrm{Bc}$ & $60 \mathrm{~A}$ & $55 \mathrm{Bb}$ & $66 \mathrm{~A}$ & $60 \mathrm{Bc}$ \\
\hline Half Plus & $60 \mathrm{Ba}$ & $68 \mathrm{Aa}$ & $66^{\mathrm{ns}}$ & $69 \mathrm{a}^{\mathrm{ns}}$ & $70 \mathrm{~B}$ & $74 \mathrm{Aa}$ \\
\hline Ácido giberélico & $48 \mathrm{Bb}$ & $54 \mathrm{Ab}$ & $60^{\text {ns }}$ & $64 \mathrm{a}^{\mathrm{ns}}$ & $61 \mathrm{~B}$ & $66 \mathrm{Ab}$ \\
\hline Média & 36 & 36 & 61 & 49 & 65 & 56 \\
\hline \multirow[t]{2}{*}{ CV $(\%)$} & \multicolumn{2}{|c|}{9,8} & \multicolumn{2}{|c|}{10,6} & \multicolumn{2}{|c|}{7,6} \\
\hline & \multicolumn{6}{|c|}{ Comprimento da parte aérea $(\mathrm{cm})$} \\
\hline Testemunha & $0,22 \mathrm{~b}^{\mathrm{ns}}$ & $0,14 \mathrm{~b}^{\mathrm{ns}}$ & $1,13 \mathrm{c}$ & $0,49 \mathrm{c}$ & $2,86 \mathrm{Ab}$ & $1,06 \mathrm{Bb}$ \\
\hline Tiametoxam & $0,11 b^{\mathrm{ns}}$ & $0,12 b^{\text {ns }}$ & $1,76 \mathrm{~b}$ & $0,77 \mathrm{c}$ & $2,59 \mathrm{Ab}$ & $1,45 \mathrm{Bb}$ \\
\hline Half Plus & $0,15 \mathrm{Bb}$ & $0,68 \mathrm{Aa}$ & $1,96 \mathrm{~b}$ & $1,43 b$ & $2,79 b^{\text {ns }}$ & $2,33 \mathrm{a}^{\mathrm{ns}}$ \\
\hline Ácido giberélico & $0,44 \mathrm{Ba}$ & 0,76 Aa & $4,01 \mathrm{a}$ & $1,90 \mathrm{a}$ & $5,15 \mathrm{Aa}$ & $2,31 \mathrm{a}$ \\
\hline Média & 0,23 & 0,43 & 2,22 & 1,15 & 3,35 & 1,79 \\
\hline \multirow[t]{2}{*}{ CV $(\%)$} & \multicolumn{2}{|c|}{12,8} & \multicolumn{2}{|c|}{15,3} & \multicolumn{2}{|c|}{13,9} \\
\hline & \multicolumn{6}{|c|}{ Comprimento do sistema radicular $(\mathrm{cm})$} \\
\hline Testemunha & $0,97 \mathrm{Aa}$ & $0,50 \mathrm{Bb}$ & $1,82 \mathrm{Ad}$ & $1,01 \mathrm{Bb}$ & $2,21 \mathrm{Ab}$ & $1,21 \mathrm{Bc}$ \\
\hline Tiametoxam & $0,63 \mathrm{Ab}$ & $0,41 \mathrm{Bb}$ & $2,13 \mathrm{Ac}$ & $1,16 \mathrm{Bb}$ & $2,29 \mathrm{Ab}$ & $1,45 \mathrm{Bc}$ \\
\hline Half Plus & $0,63 \mathrm{Bb}$ & $1,29 \mathrm{Aa}$ & $2,57 \mathrm{Aa}$ & $1,82 \mathrm{Ba}$ & $2,89 \mathrm{Aa}$ & $2,13 \mathrm{Ba}$ \\
\hline Ácido giberélico & $0,82 \mathrm{Ba}$ & $1,16 \mathrm{Aa}$ & $2,22 \mathrm{Ab}$ & $1,62 \mathrm{Ba}$ & $2,24 \mathrm{Ab}$ & $1,76 \mathrm{Bb}$ \\
\hline Média & 0,76 & 0,84 & 2,19 & 1,41 & 2,41 & 1,64 \\
\hline $\mathrm{CV}(\%)$ & \multicolumn{2}{|c|}{16,7} & \multicolumn{2}{|c|}{11,5} & \multicolumn{2}{|c|}{9,3} \\
\hline
\end{tabular}

(Leite et al., 2003; Gazzoni, 2009). Porém, quando o crescimento da parte aérea passa a ser excessivo, a plântula desloca seus metabólitos para nutrição de folhas e colmos, em detrimento ao desenvolvimento da raiz, o que pode ocasionar inibição do crescimento de raízes, inclusive das adventícias. Essa situação foi observada no experimento em ambiente controlado, no qual o ácido giberélico estimulou basicamente o desenvolvimento da parte aérea.

Em relação ao tiametoxam, a situação foi inversa: o estímulo ao sistema radicular foi predominante sobre o crescimento da parte aérea. Sabe-se que o hormônio que regula o crescimento radicular é a citocinina, promotor da divisão celular. Portanto, o tiametoxam pode estar relacionado à regulação da atividade de citocinina dentro da planta. Contudo, é provável que o aumento no teor de citocinina seja decorrente do maior desenvolvimento radicular, pois não há alteração no número de células das plantas tratadas com esse produto. Embora o maior crescimento de raízes possa proporcionar maior absorção de água e de nutrientes em soja (Tavares et al., 2007) e algodão (Lauxen et al., 2010), esse comportamento pode variar entre espécies (Macedo \& Castro, 2011).

A resposta das plantas ao tiametoxam foi dependente da cultivar, conforme verificado para 'Irga 425', em que houve crescimento equivalente entre raiz e parte aérea, o que não foi diferente do observado para o ácido giberélico. Esse resultado influenciou a resposta do teste de germinação, pois o tiametoxam produziu uma plântula de crescimento uniforme. Possivelmente, o Haf Plus também tenha ocasionado efeito de uniformidade, uma vez que não houve crescimento de nenhum dos órgãos de forma isolada, mas o desenvolvimento das plântulas aparentou ser mais lento, o que pode ter refletetido na menor velocidade de germinação.

Em campo, os resultados foram influenciados pelo sistema de cultivo utilizado. Quando conduzido em sistema convencional, os resultados de estande inicial estiveram relacionados à resposta obtida em ambiente controlado, com melhor desempenho para tiametoxam na cultivar Irga 425, e ausência de resposta para Irga 424 (Tabela 2). Para o sistema pré-germinado, no entanto, o comportamento da cultivar Irga 425 foi modificado, com menor estande para o tratamento com ácido giberélico. Dois fatores foram determinantes para essa resposta: as diferenças entre os sistemas de cultivo e o efeito do ácido giberélico sobre o sistema radicular. Ao 
se considerar o alagamento antes da semeadura do arroz, alterações em relação à nutrição e à condição ambiental a qual a semente fica exposta no período inicial de germinação determinam diferenças importantes no estabelecimento da cultura. A manutenção de lâmina de água na área ocasiona alterações químicas e físicas no solo. Já as alterações de caráter químico resultam no processo de autocalagem, decorrente do processo de redução do solo (Vahl, 1999). Consequentemente, o pH é elevado para uma condição mais favorável de crescimento, o que favorece a disponibilização de nutrientes (Fageria et al., 2011). Além disso, a água tem papel termorregulador nesse sistema, pois evita quedas ou elevações acentuadas de temperatura (Figura 1). Uma condição de melhor fertilidade e com temperatura mais elevada torna a plântula menos exposta a estresses nesse ambiente. No entanto, a manutenção da lâmina de água dificulta a fixação das plântulas de arroz, as quais podem desprender-se do solo e comprometer o estabelecimento inicial da cultura. Além disso, o excessivo alongamento do mesocótilo, mencionado anteriormente, ocasionado pela aplicação de ácido giberélico, pode comprometer o desenvolvimento do sistema radicular das plântulas. A associação dessa característica com o estresse causado pela ação dos ventos e da chuva, provavelmente, é uma das causas da redução no estande inicial observada no tratamento com ácido giberélico.
No tratamento com ácido giberélico, a maior estatura das plantas foi constatada apenas no estádio V1, para a cultivar Irga 425, no sistema pré-germinado, enquanto, no sistema convencional, os sintomas de estiolamento foram verificados nas duas cultivares até V5 (Tabela 3). A diferença básica está na temperatura do ambiente para o estabelecimento da cultura (Figura 1). As temperaturas mais baixas observadas no sistema convencional podem induzir a redução de quase $50 \%$ no conteúdo endógeno de ácido giberélico nas plantas, quando entre 11 e $18^{\circ} \mathrm{C}$, o que, consequentemente, ocasiona aumento da sensibilidade a aplicações exógenas de ácido giberélico e acarreta excessivo alongamento foliar (Pinthus et al., 1989), em razão da potencialização da dose utilizada.

Além do aumento em estatura, observou-se efeito do ácido giberélico na quantidade de colmos por planta (Tabela 2) e na produção de matéria seca (Tabela 3). O estresse causado na planta atrasou a emissão de novas folhas, retardou o crescimento vegetativo e resultou em menor acúmulo de matéria seca nesse tratamento. O efeito foi mais pronunciado no sistema convencional, tendo permanecido até o estádio V5, para a cultivar Irga 425. A maior estatura e o menor acúmulo de matéria seca proporcionaram maior espaço entre plantas. A maior quantidade de área disponível no dossel vegetativo, estimula o perfilhamento do arroz (Prabha et al., 2011), o que aumentou a emissão de colmos, nos

Tabela 2. Estande inicial de plantas e número de colmos das cultivares de arroz irrigado Irga 424 e Irga 425, nos estádios V4, V5 e V9, submetidas a tratamento de sementes com substâncias com efeito de reguladores de crescimento, em sistemas de semeadura convencional e pré-germinado ${ }^{(1)}$.

\begin{tabular}{|c|c|c|c|c|c|c|c|c|}
\hline \multirow[t]{3}{*}{ Tratamento } & \multirow{2}{*}{\multicolumn{2}{|c|}{$\begin{array}{c}\text { Estande } \\
\left(\text { plantas } \mathrm{m}^{-2}\right)\end{array}$}} & \multicolumn{6}{|c|}{ Número de colmos por planta } \\
\hline & & & \multicolumn{2}{|c|}{$\mathrm{V}^{(2)}$} & \multicolumn{2}{|c|}{ V5 } & \multicolumn{2}{|c|}{ V9 } \\
\hline & Irga 424 & Irga 425 & Irga 424 & Irga 425 & Irga 424 & Irga 425 & Irga 424 & Irga 425 \\
\hline & \multicolumn{8}{|c|}{ Sistema convencional } \\
\hline Testemunha & $333^{\text {ns }}$ & $327 \mathrm{c}^{\mathrm{ns}}$ & $1,7 \mathrm{Ab}$ & $1,0 \mathrm{Bb}$ & $1,7 b^{\mathrm{ns}}$ & $1,5 \mathrm{~b}^{\mathrm{ns}}$ & $4,0 \mathrm{~A}^{\mathrm{ns}}$ & $2,5 \mathrm{Bb}$ \\
\hline Tiametoxam & $312 \mathrm{~B}$ & 484Aa & $1,6 \mathrm{Ab}$ & $1,1 \mathrm{Bb}$ & $2,4 \mathrm{Aa}$ & $1,5 \mathrm{Bb}$ & $4,2 \mathrm{~A}$ & $1,9 \mathrm{Bc}$ \\
\hline Half Plus & $308^{\mathrm{ns}}$ & $346 \mathrm{c}^{\mathrm{ns}}$ & $1,4 b^{\text {ns }}$ & $1,5 \mathrm{a}^{\mathrm{ns}}$ & $2,4 \mathrm{a}^{\mathrm{ns}}$ & $2,3 \mathrm{a}^{\mathrm{ns}}$ & $4,2 \mathrm{~A}$ & $2,8 \mathrm{Ba}$ \\
\hline Ácido giberélico & $353 \mathrm{~B}$ & $431 \mathrm{Ab}$ & $2,3 \mathrm{Aa}$ & $1,2 \mathrm{Bb}$ & $2,5 \mathrm{Aa}$ & $1,8 \mathrm{Bb}$ & $3,6^{\mathrm{ns}}$ & $3,1 \mathrm{a}^{\mathrm{ns}}$ \\
\hline Média & 322 & 381 & 1,5 & 1,2 & 2,4 & 1,6 & 3,9 & 2,7 \\
\hline \multirow[t]{2}{*}{ CV $(\%)$} & \multicolumn{2}{|c|}{9,2} & \multicolumn{2}{|c|}{15,6} & \multicolumn{2}{|c|}{13,3} & \multicolumn{2}{|c|}{10,9} \\
\hline & \multicolumn{8}{|c|}{ Sistema pré-germinado } \\
\hline Testemunha & $184 \mathrm{~B}^{\mathrm{ns}}$ & 248Aa & $2,8 \mathrm{~A}^{\mathrm{ns}}$ & $2,1 \mathrm{~B}^{\mathrm{ns}}$ & $5,0 \mathrm{Aa}$ & $2,4 \mathrm{Bb}$ & $7,8 \mathrm{Ab}$ & $4,1 \mathrm{Bc}$ \\
\hline Tiametoxam & $200 \mathrm{~B}$ & $251 \mathrm{Aa}$ & $2,5^{\mathrm{ns}}$ & $2,3^{\mathrm{ns}}$ & $3,4 \mathrm{Ac}$ & $3,0 \mathrm{Ba}$ & $7,7 \mathrm{Ab}$ & $5,1 \mathrm{Bb}$ \\
\hline Half Plus & 149B & 219Aa & $2,8 \mathrm{~A}$ & $2,1 \mathrm{~B}$ & $4,8 \mathrm{Aa}$ & $2,5 \mathrm{Bb}$ & $8,8 \mathrm{Aa}$ & $5,4 \mathrm{Bb}$ \\
\hline Ácido giberélico & $172^{\mathrm{ns}}$ & $176 b^{\mathrm{ns}}$ & $2,9 \mathrm{~A}$ & $1,9 \mathrm{~B}$ & $3,9 \mathrm{Ab}$ & $3,2 \mathrm{Ba}$ & $8,8 \mathrm{Aa}$ & $6,6 \mathrm{Ba}$ \\
\hline Média & 182 & 229 & 2,7 & 2,0 & 4,2 & 2,8 & 8,0 & 5,0 \\
\hline $\mathrm{CV}(\%)$ & \multicolumn{2}{|c|}{13,2} & \multicolumn{2}{|c|}{10,0} & \multicolumn{2}{|c|}{9,0} & \multicolumn{2}{|c|}{8,0} \\
\hline
\end{tabular}

${ }^{(1)}$ Médias seguidas de letras iguais, minúsculas na comparação entre produtos e maiúsculas na comparação entre cultivares, não diferem, entre si, pelo teste de Scott-Knott, a 5\% de probabilidade. ${ }^{(2)}$ Escala fenológica do arroz irrigado segundo Counce et al. (2000). 
dois sistemas de cultivo avaliados. Paralelamente a isso, o Haf Plus foi eficiente em estimular o perfilhamento das duas cultivares de arroz, independentemente do sistema utilizado, o que acarretou maior acúmulo de matéria seca até o estádio V5. Esse produto apresenta constituição basicamente orgânica, rica em nutrientes, principalmente nitrogênio, que é determinante na emissão de colmos em gramíneas (Zheng et al., 2008). Com isso, há incremento na biomassa vegetal.

Os componentes de produtividade foram afetados pelos produtos (Tabela 4). Houve incremento no número de panículas por metro quadrado, em comparação à testemunha. Porém, cada cultivar respondeu de forma diferenciada dentro de cada sistema. No sistema convencional, na cultivar Irga 424, o ácido giberélico apresentou $15 \%$ a mais de panículas que os demais tratamentos. Esse resultado foi consequência direta de um maior perfilhamento (Yoshida, 1981). No sistema pré-germinado, o ácido giberélico foi acompanhado do tiametoxam, com acréscimo de $11 \%$ de panículas quando comparados à testemunha. Para a cultivar Irga 425 , todos os produtos proporcionaram $22 \%$ a mais de panículas que a testemunha, resultado que se repetiu no sistema pré-germinado, com o mesmo incremento.
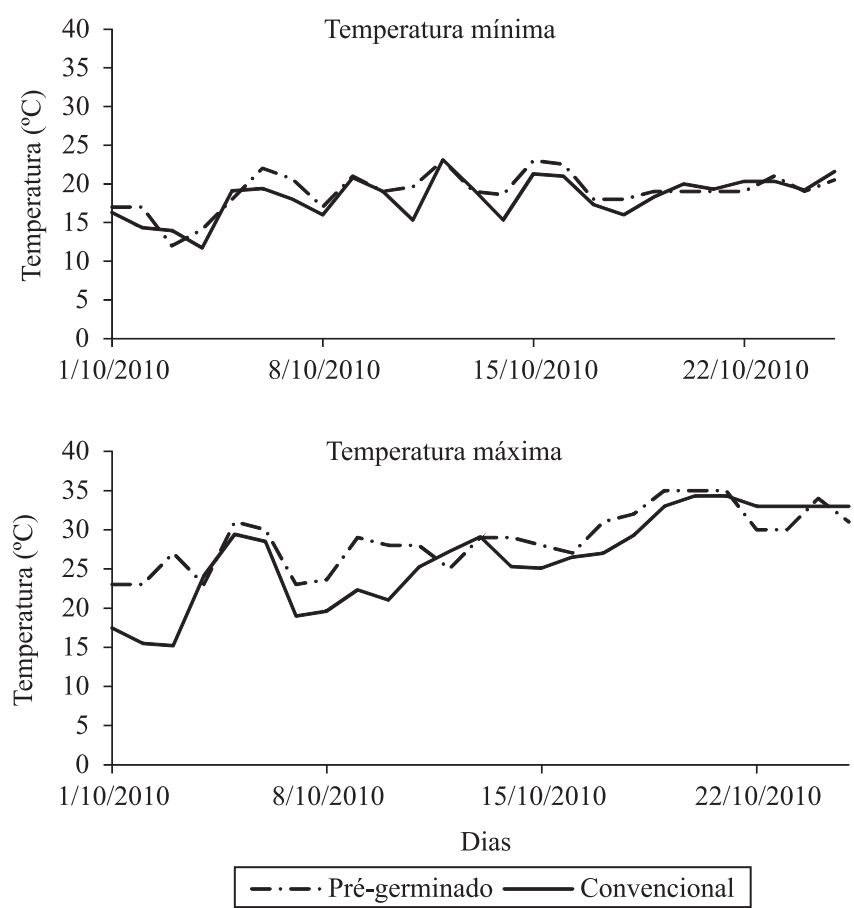

Figura 1. Temperatura mínima e máxima nos sistemas de cultivo convencional e pré-germinado, do dia da semeadura (1/10) ao estádio V2 (25/10), em Santa Maria, 2012.
Apesar da influência dos produtos até a pré-colheita, não houve diferença significativa na produtividade, nos dois sistemas avaliados. Foi observada alta esterilidade de, no tratamento com ácido giberélico na cultivar Irga 424, no sistema pré-germinado. Esse efeito do ácido giberélico foi relatado em estudos anteriores (Kariali \& Mohapatra, 2007), que atribuíram essa elevada esterilidade a perfilhos terciários, pois o ácido giberélico induz o crescimento da planta-mãe e dos perfilhos primários, os quais exercem maior competição na partição da biomassa.

Tabela 3. Estatura de plantas e produção de matéria seca das cultivares de arroz irrigado Irga 424 e Irga 425, submetidas ao uso de substâncias com efeito de reguladores de crescimento, em sistemas de semeadura convencional e pré-germinado, nos estádios de desenvolvimento V1, V3 e V5 ${ }^{(1)}$.

\begin{tabular}{|c|c|c|c|c|c|c|}
\hline \multirow[t]{2}{*}{ Tratamento } & \multirow{2}{*}{\multicolumn{2}{|c|}{$\frac{\mathrm{V} 4^{(2)}}{\operatorname{Irga} 424 \operatorname{Irga} 425}$}} & \multicolumn{2}{|c|}{ V5 } & \multicolumn{2}{|c|}{ V9 } \\
\hline & & & Irga 424 & Irga 425 & Irga 424 & Irga 425 \\
\hline & \multicolumn{6}{|c|}{ Estatura de plantas $(\mathrm{cm})$, sistema convencional } \\
\hline Testemunha & $8,3 \mathrm{~b}^{\mathrm{ns}}$ & $8,2^{\text {ns }}$ & $9,4 b^{\mathrm{ns}}$ & $10,3 b^{\mathrm{ns}}$ & $25,1 \mathrm{a}^{\mathrm{ns}}$ & $24,3 b^{\text {ns }}$ \\
\hline Tiametoxam & $7,5 \mathrm{~b}^{\mathrm{ns}}$ & $8,9^{\mathrm{ns}}$ & $8,7 \mathrm{Ab}$ & $11,5 \mathrm{Bb}$ & $22,6 \mathrm{Bb}$ & $25,4 \mathrm{Aa}$ \\
\hline Half Plus & $7,8 \mathrm{~b}^{\mathrm{ns}}$ & $8,4^{\text {ns }}$ & $10,6 \mathrm{Ab}$ & $12,3 \mathrm{Ba}$ & $23,0 \mathrm{Bb}$ & $26,9 \mathrm{Aa}$ \\
\hline Ácido giberélico & $12,4 \mathrm{Aa}$ & $10,1 \mathrm{~B}$ & $17,8 \mathrm{Aa}$ & $12,8 \mathrm{Ba}$ & $25,6 \mathrm{Ba}$ & $22,9 \mathrm{Ab}$ \\
\hline Média & 9,0 & 8,9 & 11,6 & 11,7 & 24,1 & 24,9 \\
\hline \multirow[t]{2}{*}{ CV $(\%)$} & \multicolumn{2}{|c|}{13,4} & \multicolumn{2}{|c|}{11,0} & \multicolumn{2}{|c|}{6,8} \\
\hline & \multicolumn{6}{|c|}{ Estatura de plantas $(\mathrm{cm})$, sistema pré-germinado } \\
\hline Testemunha & $13,3^{\text {ns }}$ & $13,8 b^{\text {ns }}$ & $21,3^{\text {ns }}$ & $20,5^{\mathrm{ns}}$ & $30,9 b^{\text {ns }}$ & $30,9 b^{\text {ns }}$ \\
\hline Tiametoxam & 14,9 & $15,7 \mathrm{a}$ & 22,0 & 21,2 & $34,3 \mathrm{a}$ & $33,7 \mathrm{a}$ \\
\hline Half Plus & 14,6 & $14,0 \mathrm{~b}$ & 22,2 & 21,8 & $32,4 \mathrm{~b}$ & $32,1 \mathrm{~b}$ \\
\hline Ácido giberélico & 15,0 & $13,6 \mathrm{~b}$ & 21,4 & 20,9 & $31,5 \mathrm{~b}$ & $33,1 \mathrm{a}$ \\
\hline Média & 14,5 & 14,3 & 21,7 & 21,1 & 32,3 & 32,4 \\
\hline \multirow[t]{2}{*}{ CV $(\%)$} & \multicolumn{2}{|c|}{9,2} & \multicolumn{2}{|c|}{4,0} & \multicolumn{2}{|c|}{3,1} \\
\hline & \multicolumn{6}{|c|}{ Massa de matéria seca $\left(\mathrm{kg} \mathrm{ha}^{-1}\right)$, sistema convencional } \\
\hline Testemunha & $31 \mathrm{~A}^{\mathrm{ns}}$ & $27 \mathrm{Bc}$ & $75 \mathrm{a}^{\mathrm{ns}}$ & $79 \mathrm{~b}^{\mathrm{ns}}$ & $469 \mathrm{Bc}$ & 734Ac \\
\hline Tiametoxam & $30 \mathrm{~B}$ & $42 \mathrm{Aa}$ & $59 \mathrm{Bc}$ & $94 \mathrm{Aa}$ & $437 \mathrm{Bc}$ & $954 \mathrm{Ab}$ \\
\hline Half Plus & $31^{\mathrm{ns}}$ & $34 \mathrm{~b}^{\mathrm{ns}}$ & $64 \mathrm{Ba}$ & 89Aa & $608 \mathrm{Bb}$ & $1.190 \mathrm{Aa}$ \\
\hline Ácido gibrélico & $30^{\mathrm{ns}}$ & $33 b^{\text {ns }}$ & $45 \mathrm{c}^{\mathrm{ns}}$ & $48 \mathrm{c}^{\mathrm{ns}}$ & $1.162 \mathrm{Aa}$ & $717 \mathrm{Bc}$ \\
\hline Média & 30 & 34 & 60 & 77 & 669 & 899 \\
\hline \multirow[t]{2}{*}{ CV $(\%)$} & \multicolumn{2}{|c|}{10,2} & \multicolumn{2}{|c|}{10,5} & \multicolumn{2}{|c|}{14,0} \\
\hline & \multicolumn{6}{|c|}{ Massa de matéria seca $\left(\mathrm{kg} \mathrm{ha}^{-1}\right)$, sistema pré-germinado } \\
\hline Testemunha & $22 b^{n s}$ & $22 \mathrm{~b}^{\mathrm{ns}}$ & $60 \mathrm{a}^{\mathrm{ns}}$ & $68^{\mathrm{ns}}$ & $632^{\mathrm{ns}}$ & $601 b^{\mathrm{ns}}$ \\
\hline Tiametoxam & $26 \mathrm{Aa}$ & $23 \mathrm{Bb}$ & $60 \mathrm{a}^{\mathrm{ns}}$ & $56^{\mathrm{ns}}$ & $579^{\text {ns }}$ & $574 \mathrm{~b}^{\mathrm{ns}}$ \\
\hline Half Plus & $22 \mathrm{~b}^{\mathrm{ns}}$ & $22 \mathrm{~b}^{\mathrm{ns}}$ & $64 \mathrm{a}^{\mathrm{ns}}$ & $64^{\mathrm{ns}}$ & $651 \mathrm{~B}$ & $834 \mathrm{Aa}$ \\
\hline Ácido giberélico & $19 \mathrm{Bc}$ & $30 \mathrm{Aa}$ & $43 \mathrm{Bb}$ & $61 \mathrm{~A}$ & $535^{\mathrm{ns}}$ & $569 \mathrm{~b}^{\mathrm{ns}}$ \\
\hline Média & 22 & 24 & 57 & 62 & 599 & 644 \\
\hline $\mathrm{CV}(\%)$ & \multicolumn{2}{|c|}{7,9} & \multicolumn{2}{|c|}{10,0} & \multicolumn{2}{|c|}{11,7} \\
\hline
\end{tabular}

Pesq. agropec. bras., Brasília, v.47, n.6, p.776-783, jun. 2012 
Tabela 4. Componentes de produção das cultivares de arroz irrigado Irga 424 e Irga 425, submetidas ao uso de substâncias com efeito de reguladores de crescimento, em sistemas de semeadura convencional e pré-germinado ${ }^{(1)}$.

\begin{tabular}{|c|c|c|c|c|c|c|}
\hline \multirow[t]{2}{*}{ Tratamento } & \multicolumn{2}{|c|}{ Panículas por $\mathrm{m}^{-2}$} & \multicolumn{2}{|c|}{ Produtividade $\left(\mathrm{kg} \mathrm{ha}^{-1}\right)$} & \multicolumn{2}{|c|}{ Esterilidade (\%) } \\
\hline & Irga 424 & Irga 425 & Irga 424 & Irga 425 & Irga 424 & Irga 425 \\
\hline & \multicolumn{6}{|c|}{ Sistema convencional } \\
\hline Testemunha & $668 \mathrm{Ab}^{(2)}$ & $500 \mathrm{Bb}$ & $10.645^{\mathrm{ns}}$ & $10.122^{\mathrm{ns}}$ & $10,2 \mathrm{a}^{\mathrm{ns}}$ & $10,4^{\mathrm{ns}}$ \\
\hline Tiametoxam & $682 \mathrm{Ab}$ & $594 \mathrm{Ba}$ & $11.126^{\mathrm{ns}}$ & $10.729^{\text {ns }}$ & $9,0 \mathrm{Ba}$ & $10,5 \mathrm{a}$ \\
\hline Half Plus & $643 b^{\text {ns }}$ & $612 \mathrm{a}^{\mathrm{ns}}$ & $10.974^{\mathrm{ns}}$ & $10.001^{\mathrm{ns}}$ & $5,4 \mathrm{Bb}$ & $11,3 \mathrm{a}$ \\
\hline Ácido giberélico & 787Aa & $612 \mathrm{Ba}$ & $11.331 \mathrm{~A}$ & $9.341 \mathrm{~B}$ & $5,3 \mathrm{Bb}$ & $9,7 \mathrm{a}$ \\
\hline Média & 694 & 571 & 11.019 & 10.050 & 7,5 & 10,5 \\
\hline \multirow[t]{2}{*}{ CV (\%) } & \multicolumn{2}{|c|}{9,0} & \multicolumn{2}{|c|}{8,5} & \multicolumn{2}{|c|}{5,5} \\
\hline & \multicolumn{6}{|c|}{ Sistema pré-germinado } \\
\hline Testemunha & $896 \mathrm{Ab}$ & $626 \mathrm{Bb}$ & $9.686 \mathrm{~A}^{\mathrm{ns}}$ & $7.789 \mathrm{~B}^{\mathrm{ns}}$ & $8,5 \mathrm{~b}^{\mathrm{ns}}$ & $7,8 \mathrm{a}^{\mathrm{ns}}$ \\
\hline Tiametoxam & $985 \mathrm{Aa}$ & $731 \mathrm{Ba}$ & $9.562 \mathrm{~A}$ & $8.120 \mathrm{~B}$ & 7,9Ab & $5,7 \mathrm{Bb}$ \\
\hline Half Plus & $795 c^{n s}$ & $728 a^{\text {ns }}$ & $9.417 \mathrm{~A}$ & $7.474 \mathrm{~B}$ & $5,3 \mathrm{Bc}$ & $6,9 \mathrm{Aa}$ \\
\hline Ácido giberélico & 997Aa & $759 \mathrm{Ba}$ & $9.144 \mathrm{~A}$ & $7.916 \mathrm{~B}$ & $13,4 \mathrm{Aa}$ & $4,4 \mathrm{Bb}$ \\
\hline Média & 897 & 703 & 9.452 & 7.825 & 8,8 & 6,2 \\
\hline CV (\%) & \multicolumn{2}{|c|}{7,5} & \multicolumn{2}{|c|}{6,1} & \multicolumn{2}{|c|}{4,3} \\
\hline
\end{tabular}

${ }^{(1)}$ Médias seguidas de letras iguais, minúsculas na comparação entre produtos e maiúsculas na comparação entre cultivares, não diferem, entre si, pelo teste de Scott-Knott, a 5\% de probabilidade.

\section{Conclusões}

1. Em ambiente controlado, as substâncias com efeito de reguladores de crescimento estimulam a germinação das sementes, de acordo com a cultivar utilizada.

2. Essas substâncias, quando utilizadas a campo, apresentam maior influência sobre as plantas cultivadas no sistema convencional, efeito que também é dependente da cultivar utilizada.

3. O ácido giberélico causa efeitos negativos no desempenho inicial das cultivares, enquanto o Tiametoxam e o Haf Plus estimulam o perfilhamento das cultivares de arroz, nos dois sistemas de cultivo.

4. Apesar de todos os produtos utilizados estimularem o número de panículas por metro quadrado, não há influencia na produtividade de grãos, independentemente do sistema de cultivo utilizado.

\section{Referências}

ARROZ IRRIGADO: recomendações técnicas da pesquisa para o Sul do Brasil 28. Bento Gonçalves: Sociedade Sul-Brasileira de Arroz Irrigado, 2010. 188p.

COUNCE, P.A.; KEISLING, T.C.; MITCHELL, A.J. A uniform, objective, and adaptive system for expressing rice development. Crop Science, v.40, p.436-443, 2000.

CRUZ, R.P. da; DUARTE, I.T. de L.; CABREIRA, C. Inheritance of rice cold tolerance at the seedling stage. Scientia Agricola, v.67, p.669-674, 2010.
DAI, C.; XUE, H. Rice early flowering1, a CKI, phosphorylates DELLA protein SLR1 to negatively regulate gibberellin signaling. EMBO Journal, v.29, p.1916-1927, 2010.

FAGERIA, N.K.; CARVALHO, G.D.; SANTOS,A.B.; FERREIRA, E.P.B.; KNUPP, A.M. Chemistry of lowland rice soils and nutrient availability. Communications in Soil Science and Plant Analysis, v.42, p.1913-1933, 2011.

FAROOQ, M.; SIDDIQUE, K.H.M.; REHMAN, H.; AZIZ, T.; LEE, D.; WAHID, A. Rice direct seeding: experiences, challenges and opportunities. Soil and Tillage Research, v.111, p.87-98, 2011.

FORD, K.A.; CASIDA, J.E.; CHANDRAN, D.; GULEVICH, A.G.; OKRENT, R.A.; DURKIN, K.A.; SARPONG, R.; BUNNELLE, E.M.;WILDERMUTH, M.C. Neonicotinoid insecticides induce salicylate-associated plant defense responses. Proceedings of the National Academy of Sciences of the United States of America, v.107, p.17527-17532, 2010.

GAZZONI, D.L. Hormônios vegetais. In: GAZZONI, D.L. (Ed.). Tiametoxam: uma revolução na agricultura brasileira. São Paulo: Vozes, 2009.

HORII, A.; MCCUE, P.; SHETTY, K. Enhancement of seed vigour following insecticide and phenolic elicitor treatment. Bioresource Technology, v.98, p.623-632, 2007.

ISMAIL, A.M.; ELLA, E.S.; VERGARA, G.V.; MACKILL, D.J. Mechanisms associated with tolerance for flooding during germination and early seedling growth in rice (Oryza sativa). Annals of Botany, v.103, p.197-209, 2009.

KARIALI, E.; MOHAPATRA, P.K. Hormonal regulation of tiller dynamics in differentially-tillering rice cultivars. Plant Growth Regulation, v.53, p.215-223, 2007.

KÜLEN, O.; STUSHNOFF, C.; DAVIDSON, R.D.; HOLM, D.G.M. Gibberellic acid and ethephon alter potato minituber bud 
dormancy and improve seed tuber yield. American Journal of Potato Research, v.88, p.167-174, 2011.

LAUXEN, L.R.; VILLELA, F.A.; SOARES, R.C. Desempenho fisiológico de sementes de algodoeiro tratadas com tiametoxam. Revista Brasileira de Sementes, v.32, p.61-68, 2010.

LEITE, V.M.; ROSOLEM, C.A.; RODRIGUES, J.D. Gibberellin and cytokinin effects on soybean growth. Scientia Agricola, v.60, p.537-541, 2003.

MACEDO, W.R.; CASTRO, P.R. de C. Thiamethoxam: molecule moderator of growth, metabolism and production of spring wheat. Pesticide Biochemistry and Physiology, v.100, p.299-304, 2011.

MARCHEZAN, E.; GARCIA, G.A.; CAMARGO, E.R.; MASSONI, P.F.S.; AROSEMENA, D.R.; OLIVEIRA, A.P.B.B. de. Manejo da irrigação em cultivares de arroz no sistema pré-germinado. Ciência Rural, v.37, p.45-50, 2007.

MARCHEZAN, E.; RABAIOLI, E.C.; LOPES, S.I.G.; SANTOS, F.M. dos; MICHELON, S. Desempenho de genótipos de arroz irrigado cultivados no sistema pré-germinado com inundação contínua. Ciência rural, v.34, p.1349-1354, 2004.

O'BRIEN, R.; FOWKES, N.; BASSOM, A.P. Models for gibberellic acid transport and enzyme production and transport in the aleurone layer of barley. Journal of Theoretical Biology, v.267, p.15-21, 2010.

PINTHUS, M.J.; GALE, M.D.; APPLEFORD, N.E.J.; LENTON, J.R. Effect of temperature on gibberellin (GA) responsiveness and on endogenous $\mathrm{GA}_{1}$ content of tall and dwarf wheat genotypes. Plant Physiology, v.90, p.854-859, 1989.

PRABHA, A.C.S.; THIYAGARAJAN, T.M.; SENTHIVELU, M. System of rice intensification principles on growth parameters, yield attributes and yields of rice (Oryza sativa L.). Journal of Agronomy, v.10, p.27-33, 2011.

RAYORATH, P.; KHAN, W.; PALANISAMY, R.; MACKINNON, S.L.; STEFANOVA, R.; HANKINS, S.D.; CRITCHLEY, A.T.;
PRITHIVIRAJ, B. Extracts of the Brown Seaweed Ascophyllum nodosum induce gibberellic acid $\left(\mathrm{GA}_{3}\right)$-independent amylase activity in barley. Journal of Plant Growth Regulation, v.27, p.370-379, 2008.

REGRAS para análise de sementes. Brasília: MAPA, 2009. 399p.

SANTOS, H.G. dos; JACOMINE, P.K.T.; ANJOS, L.H.C. dos; OLIVEIRA, V.A. de; OLIVEIRA, J.B. de; COELHO, M.R.; LUMBRERAS, J.F.; CUNHA, T.J.F. (Ed.). Sistema brasileiro de classificação de solos. 2.ed. Rio de Janeiro: Embrapa Solos, 2006. $306 \mathrm{p}$.

SILVA, R.H. da; LAURETTI, R.L.B.; CRUSCIOL, C.A.C.; ANDREOTTI, M.; GONÇALVES, J.R.P. Estabelecimento de plantas e produtividade de grãos de duas cultivares de arroz no sistema pré-germinado. Acta Scientiarum, v.24, p.1413-1418, 2002.

TAVARES, S.; CASTRO, P.R.C.; RIBEIRO, R.V.; ARAMAKI, P.H. Avaliação dos efeitos fisiológicos de tiametoxam no tratamento de sementes de soja. Revista de Agricultura, v.82, p.47-54, 2007.

TINARELLI, A. El arroz. 2.ed. Madrid: Mundi-Prensa, 1989. $575 \mathrm{p}$.

VAHL, L.C. Fertilidade de solos de várzea. In: GOMES, A. da S.; PAULETTO, E.A. (Ed.). Manejo do solo e da água em áreas de várzea. Pelotas: Embrapa-CPACT, 1999. p.119-162.

YAMAGUCHI, S. Gibberellin metabolism and its regulation. Annual Review of Plant Biology, v.59, p.225-251, 2008.

YOSHIDA, S. Fundamentals of rice crop science. Los Baños: International Rice Research Institute, 1981. 269p.

ZHENG, Y.-M.; DING, Y.-F.; WANG, Q.-S; LI, G.-H.; WANG, H.-Z.; WANG, S.-H. Effect of nitrogen applied before transplanting on tillering and nitrogen utilization in rice. Acta Agronomica Sinica, v.34, p.513-519, 2008.

$\overline{\text { Recebido em } 21 \text { de janeiro de } 2012 \text { e aprovado em } 30 \text { de maio de } 2012}$ 